Provided for non-commercial research and education use. Not for reproduction, distribution or commercial use.

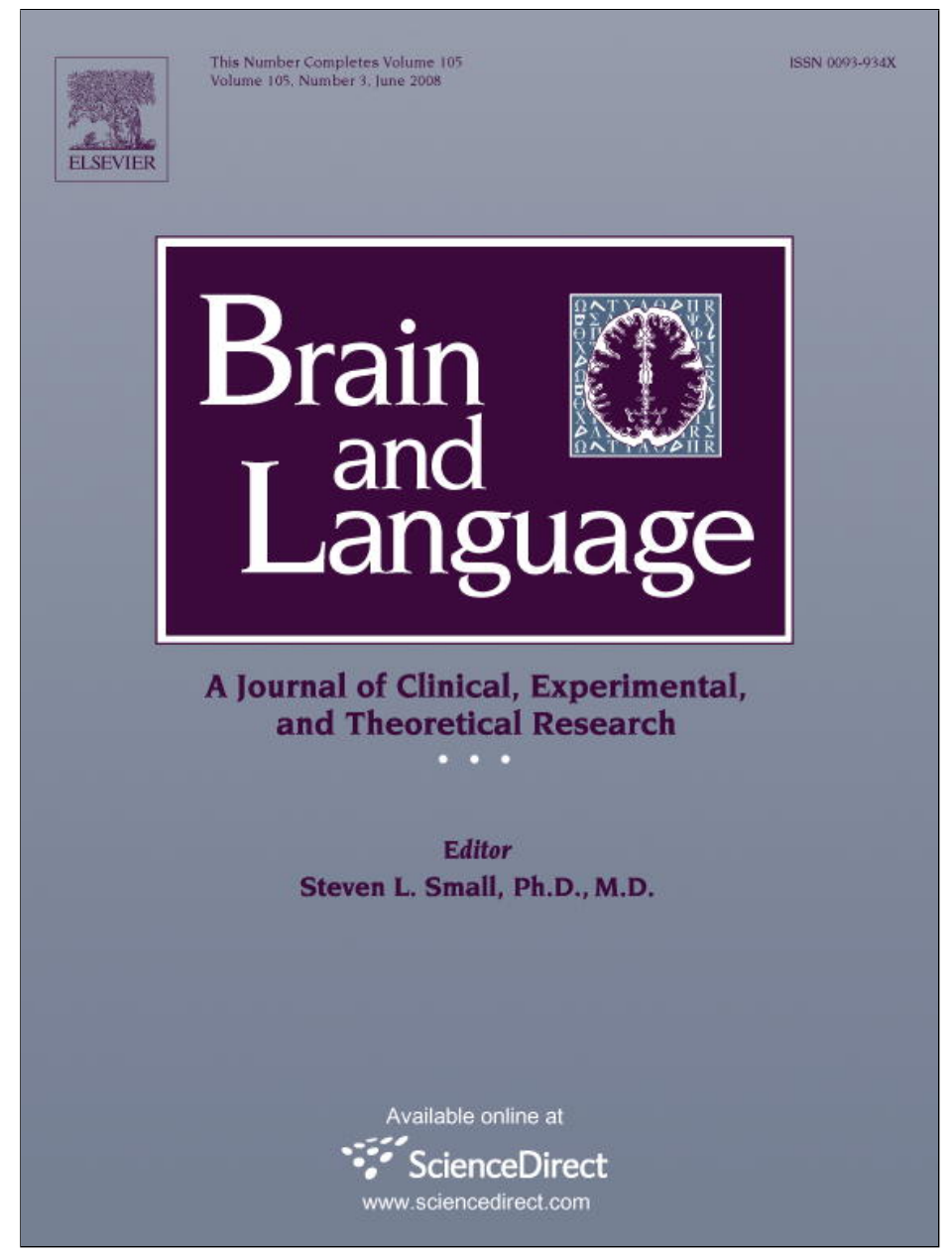

This article appeared in a journal published by Elsevier. The attached copy is furnished to the author for internal non-commercial research and education use, including for instruction at the authors institution and sharing with colleagues.

Other uses, including reproduction and distribution, or selling or licensing copies, or posting to personal, institutional or third party websites are prohibited.

In most cases authors are permitted to post their version of the article (e.g. in Word or Tex form) to their personal website or institutional repository. Authors requiring further information regarding Elsevier's archiving and manuscript policies are encouraged to visit:

http://www.elsevier.com/copyright 


\title{
Spoken-word processing in aphasia: Effects of item overlap and item repetition
}

\author{
Esther Janse * \\ Utrecht Institute of Linguistics OTS, Utrecht University, Janskerkhof 13, 3512 BL Utrecht, The Netherlands
}

Accepted 16 October 2007

Available online 19 November 2007

\begin{abstract}
Two studies were carried out to investigate the effects of presentation of primes showing partial (word-initial) or full overlap on processing of spoken target words. The first study investigated whether time compression would interfere with lexical processing so as to elicit aphasic-like performance in non-brain-damaged subjects. The second study was designed to compare effects of item overlap and item repetition in aphasic patients of different diagnostic types. Time compression did not interfere with lexical deactivation for the non-brain-damaged subjects. Furthermore, all aphasic patients showed immediate inhibition of co-activated candidates. These combined results show that deactivation is a fast process. Repetition effects, however, seem to arise only at the longer term in aphasic patients. Importantly, poor performance on diagnostic verbal STM tasks was shown to be related to lexical decision performance in both overlap and repetition conditions, which suggests a common underlying deficit.
\end{abstract}

(C) 2007 Elsevier Inc. All rights reserved.

Keywords: Spoken-word processing; Aphasia; Inhibition; Lexical activation; Priming; Lexical deactivation; Repetition priming

\section{Introduction}

During auditory word recognition, lexical word candidates compete for recognition and influence each other's activation levels. Evidence for lateral inhibition between competing word candidates comes from interference effects found with high-similarity word-initial form-overlap between a prime (e.g., difficult) and a following target (e.g., diffident; cf. Monsell \& Hirsh, 1998; Slowiaczek \& Hamburger, 1992). When the prime is being processed, several word candidates compete. In the TRACE (McClelland \& Elman, 1986) model of auditory word recognition, there are direct inhibitory connections between words. An increase in the level of activation of one candidate then automatically leads to a decrease in the activation level of others. McClelland and Elman (1986) claim that this 'winner-takes-all' principle makes the recognition process more

\footnotetext{
* Now also at Max Planck Institute for Psycholinguistics, Nijmegen, The Netherlands. Fax: +31 302536406 .

E-mail address: esther.janse@let.uunl
}

efficient. Once one of the candidates has been isolated and recognised, the other candidates are decreased in activation. When one of these once-activated candidates is subsequently presented as the next item, recognition of this item is inhibited, relative to unrelated (control) targets. Monsell and Hirsh (1998) describe the competitor interference effect (i.e., slower lexical decision responses to diffident if preceded by difficult than if preceded by an unrelated control word) and the facilitatory effect of repetition (faster lexical decision responses to diffident if preceded by diffident than if preceded by an unrelated control word) as two sides of the same coin: recognition of a word makes it easier to recognise on the next encounter, but at the cost of making similar words (i.e, onset-overlapping words) more difficult to recognise.

Whereas theories as TRACE describe the competition process as "lateral" inhibition between several lexical candidates, others have argued for bottom-up inhibition: if there is a mismatch between the input form and the lexical entry's form, activation of that candidate is lowered (Marslen-Wilson, Moss, \& van Halen, 1996; Marslen-Wilson \& 
Warren, 1994). The extent to which activation is lowered may be gradient: in the shortlist model of word recognition (Norris, 1994), mismatching information may deactivate a lexical entry depending on the phonological distance between the input signal and the form of the lexical entry. Frauenfelder, Scholten, and Content (2001) found evidence for bottom-up inhibition in a study in which they investigated to which extent later-arriving mismatching information (e.g., in the French pseudoword vocabulaise, initially activating the entry vocabulaire) reduced the activation provided by earlier matching information. Their results obtained with pseudowords show that spoken-word recognition models need to include some form of bottom-up inhibition. (Partial) deactivation must have occurred through bottom-up mismatch, rather than through lateral inhibition, because there was no winning lexical candidate in the end. Inhibition in spoken-word recognition, as in found in studies with onset-overlapping real-word primes and target words (cf. the difficult-diffident example), can be the result of either bottom-up deactivation or of lateral deactivation, or of both.

McNellis and Blumstein (2001) developed a model describing the process of auditory word recognition in aphasia. They argue that lexical-processing impairments in aphasia are due to alterations in the dynamics of lexical activation, and the resulting spread of activation from one lexical representation to another. Furthermore, the deficit in the dynamics of lexical activation is different for Broca's and Wernicke's aphasics: whereas nonfluent or Broca's aphasic patients seem to have initial underactivation of the lexicon, compared to a non-brain-damaged control group, fluent or Wernicke's aphasic listeners have been claimed to show increased lexical activation (cf. Milberg, Blumstein, \& Dworetzky, 1988; Misiurski, Blumstein, Rissman, \& Berman, 2005; Utman, Blumstein, \& Sullivan, 2001, but also see Baum, 1997; Gordon \& Baum, 1994). Following Dell, Schwartz, Martin, Saffran, and Gagnon (1997) who modelled aphasic speech production errors by making global parameter adjustments to the 'normal' model, McNellis and Blumstein (2001) altered the parameter of lexical resting state to lower-than-normal for Broca's and to higher-than-normal for Wernicke's aphasics. McNellis and Blumstein showed that by such a simple parameter adjustment, experimental findings of Milberg et al. (1988) and of Utman et al. (2001) could be simulated. Thus, the effect of brain damage can be regarded in terms of systemic properties, rather than in terms of impairment of specific functions localisable in the brain (cf. Dell et al., 1997; Laine, Tikkala, \& Juhola, 1998; McNellis \& Blumstein, 2001). In this view, normal performance is the upper limit of a performance continuum and aphasic performance is spread over the continuum.

Whereas the Broca's aphasic patients seem to have difficulty in activation of word candidates (Misiurski et al., 2005; Utman et al., 2001), deactivation of inappropriate candidates seems to be the main problem for Wernicke's aphasics. This was also found in an eye-tracking study
(Yee, Blumstein, \& Sedivy, 2004) in which the effect of onset competitors was investigated for Wernicke's patients. When presented with an auditory stimulus (e.g., camera), Wernicke's patients fixated longer on onset-overlapping distractors (such as camel) than control adults. This implies that, even in the presence of negative bottom-up information, these patients are impaired in the deactivation of once-appropriate word candidates. The results from an adapted Stroop color word test by Wiener, Connor, and Obler (2004) also showed a larger Stroop interference effect for Wernicke's aphasic patients than for an age-matched control population.

Further confirmation for this impaired deactivation was found in a study specifically designed to investigate lexical competition effects in Wernicke's aphasia (Janse, 2006). The results showed inhibition in the overlap condition for the control adults (prime salaris 'salary' preceding target salami 'salami'), but facilitation was found in this same condition for the Wernicke's aphasic patients. Even after several intervening items, co-activated word candidates showed persisting activation for the Wernicke's aphasic patients. The present study elaborates on this finding in two ways.

First, there is evidence that aphasic receptive deficits in syntax processing can be elicited in unimpaired subjects under stressful conditions (Dick et al., 2001). This is the other side of the continuity hypothesis coin: if normal performance is the upper limit of the continuum and aphasic performance is spread over the continuum, then normals can be "made to perform in an aphasic way" when put under pressure. Time compression of speech has been shown to eliminate inhibitory effects found at a normal speech rate, without affecting the size of facilitatory effects (Aydelott \& Bates, 2004). This suggests that facilitation through spreading of activation in the semantic network occurs rapidly, whereas inhibition is a slower process that can be affected by attentional demand. Importantly, the Aydelott and Bates (2004) results concerned inhibitory or facilitatory effects of a preceding sentence context.

The first part of the present study (Part I) was set up to investigate whether and how reduced-processing-time interferes with effects on the lexical-level due to word-initial item overlap or item repetition. If inhibition is a relatively slow process, the lack of lateral inhibition between competing word candidates observed in Janse (2006) may be elicited in young non-brain-damaged listeners. This was operationalised by applying time compression: it was investigated whether lexical-level inhibitory effects are also modified or eliminated by moderate time compression, as found for sentence-level inhibitory effects in Aydelott and Bates (2004). A second question was whether facilitation through item repetition is affected by moderate time compression. Auditory word recognition is known to be facilitated by an earlier auditory encounter with the same word: both in case it has just been said, but the effect is also seen over lags of hours or weeks (cf. Monsell \& Hirsh, 1998). If these repetition priming effects still occur over such long lags, 
they cannot be attributed to persistence of activation, but note that greater repetition priming effects are found with short time intervals between the first and second presentation than with longer intervals (e.g., with numerous items intervening between the first and second presentation). Thus, repetition priming has two aspects: a short-lived repetition effect due to the presence of some 'echo' representation in short-term memory, and the longer-term change in the word's representation responsible for long-lag priming effects. The effect seen over longer lags cannot possibly be attributed to the item still being residually active in shortterm memory, but may be due to the item being 'flagged' in long-term memory as 'having been encountered before'. In training a connectionist network for auditory word recognition (e.g., Plaut \& Shallice, 1993 for a visual recognition analogy), attractors must be developed for each word form. Encounters with e.g., two similar input words will pull the attractor basins of the two items apart. Every encounter with a word will slightly modify the weight (i.e., the 'flagging' that this word is encountered again) such that it will slightly change the tendency of the network to settle into that word's attractor (cf. Monsell \& Hirsh, 1998). Repetition priming and frequency effects in auditory word recognition can thus be accounted for in terms of this continuous update of a word's representation in long-term memory: there is a stronger 'bias' towards or a stronger attraction by words that have been (frequently) encountered before (cf. also Ratcliff \& McKoon, 1996, 1997).

If repetition priming is a fast process, time compression may not reduce its facilitatory effect, as was found for sentence-level facilitation in Aydelott and Bates (2004). The effect of time compression on inhibitory overlap effects was compared with its effect on facilitatory effects of item repetition in order to compare the time courses of the two priming processes.

Secondly, this study also comprises a study on effects of item overlap and item repetition in aphasia (Part II). More knowledge on the role of processing time in lexical priming effects (Part I) can be related to patient data obtained in Part II to see whether a reduced-processing-time account might suit the aphasic results. In Part II, target activation (e.g., target $=$ camel) was studied following an overlapping item (e.g., prime = camera) and following presentation of the target itself (prime $=$ camel). This was done to evaluate the degree to which co-activated competing lexical candidates remain active even after one candidate has been recognised. This direct comparison between overlap effects and repetition effects was not possible in the previous study (Janse, 2006). Furthermore, the current investigation of initial overlap and repetition priming effects in aphasia complements the study by Blumstein et al. (2000) who varied prime-target lag in a repetition priming study and found that Broca's and Wernicke's aphasic patients, unlike the control subjects, did not show increased repetition priming effects (or even absence of priming) at the shortest lags, relative to longer lags. In the current study, aphasic patients of different aphasic syndromes were included, with a focus on anomic patients' lexical-processing performance. This aphasia type is relatively frequently found among aphasic patients (cf. Heesbeen, 2001). Patients are diagnosed as having an anomic aphasia when their language problems are relatively mild, particularly their impairments in language comprehension. Their key language problem concerns word finding difficulties, which is a problem they share with the Broca's and Wernicke's aphasic patients. Even though their spoken-word comprehension should be good (by definition), subtle spoken-word-processing impairments may show up in a response time study. As proposed by Martin and colleagues (Martin, 2000; Martin \& Gupta, 2004; Martin \& Saffran, 1997), spreading activation is the common process underlying performance of single word tasks (both in word retrieval in production and in speech comprehension) as well as tasks with multiple items such as nonword repetition or repetition span. Since anomic patients, like all aphasic patients, suffer from auditory-verbal short-term memory impairments (cf. Martin \& Ayala, 2004), the question arises whether and how spoken-word-processing performance of these "mildly aphasic" patients deviates from non-brain-damaged control subjects. Anomic patients' performance will be compared to that of Broca's and Wernicke's patients. Apart from a classification into aphasia types, the lexical-processing results will also be analysed in a more continuous way by relating patients' performance to several background measures (of auditory-verbal shortterm memory and of auditory word comprehension). The choice to also include anomic patients yields more diverse performance and is related to this idea of normal performance being the upper limit of the continuum and aphasic performance spread all over the continuum. Thus, the two substudies are meant to shed more light on the processes of item inhibition and facilitation as part of spoken-word recognition, both in non-brain-damaged and in aphasic listeners. The combination of the two studies also allows us to investigate whether a reduced-processing-time account might explain the aphasic results.

\subsection{Time compression, facilitation and inhibition}

In their auditory sentence processing study, Aydelott and Bates (2004) examined the effects of acoustic distortion on semantic facilitation (by a biasing or congruent sentence context) and inhibition (by an incongruent context) of an auditory word target (e.g., On a windy day, it is nice to go out and fly a KITE/FORK). Subjects had to perform lexical decision on a auditory target item (KITE/FORK), after they had been presented with an auditory sentence context. Acoustic distortion either involved low-pass filtering or time compression of this preceding context. Importantly, the two opposite priming effects (facilitation and inhibition) were differentially affected by the two types of acoustic distortion. Low-pass filtering made the preceding sentence context less intelligible and therefore reduced facilitation, and consequently inhibition as well. Time compression, on the other hand, primarily affects central lan- 
guage processing. As long as time compression is moderate (not exceeding an acceleration factor of 2), intelligibility is relatively unaffected, but speech processing in these distortion conditions requires extra resources. Time compression of the preceding sentence context was found to significantly reduce inhibition without affecting facilitation. This confirmed earlier results that facilitation occurs rapidly, whereas inhibition is a slower process that can be affected by attentional demand: the presentation of competing speech in the other ear significantly reduced the inhibitory effect of sentence context on incongruent targets, without affecting facilitation of congruent targets (Moll, Cardillo, \& Aydelott Utman, 2001).

Thus, the Aydelott and Bates (2004) results showed that inhibition and facilitation effects at sentence-level have different time courses because inhibition effects occur relatively late. Listeners presented with time-compressed sentences (compression to $50 \%$ of the original duration) did not have enough time or processing resources to inhibit incongruent targets. The central question in Part I of the present study was whether lexical-level inhibition effects would also be eliminated by time compression, as was found for sentence-level inhibition in Aydelott and Bates (2004). In order to gain more insight into the time courses of lexical activation and deactivation, it is important to know whether time compression of isolated words also interferes with item facilitation (due to item repetition) and item inhibition (due to word-initial overlap with a competing candidate). If all inhibitory processes are particularly vulnerable to factors such as processing time or load, lexical overlap effects, be it due to lateral or bottom-up inhibition, may also be strongly reduced at short prime-target intervals if the prime word is time-compressed. As indicated, Dick et al. (2001) elicited aphasic receptive deficits in syntax processing in unimpaired subjects by making processing more stressful. Thompson-Schill (2005) related the elicited aphasic-like results of Dick et al. (2001) to the function of Broca's area to guide selection among competing sources of information. Tasks requiring more processing resources would then typically be tasks in which selection is important. Note, however, that even though Thompson-Schill relates Broca's, rather than Wernicke's area, to a selection mechanism, she states that intervention comes in the form of a modulatory signal that aids in the selection of an appropriate representation, e.g., in a Stroop task, or in reducing interference during working memory (Thompson-Schill et al., 2002). Thus, non-brain-damaged subjects may then be made to perform 'Wernicke'-like in the sense of lacking lexical deactivation (as the Wernicke's results in Janse, 2006) when put under time pressure. On the other hand, inhibitory sentence priming effects may be slower to accrue than lexical-level inhibition effects. Sentence priming may more closely reflect semantic integration processes and the generation of expectancies. These take time to build up during a sentence.

A prime-target experiment was set up to test whether and to what extent time compression of isolated lexical primes would interfere with the priming effects of item overlap and item repetition. ${ }^{1}$ In other words, the question is whether lexical inhibition, like sentence priming of incongruent word targets, is reduced in conditions with reducedprocessing-time. If the inhibitory effect of item overlap is reduced by time compression, facilitation could arise due to two effects: the first being persisting sublexical activation (phonemes or larger sublexical units are processed again), and the second being persisting lexical activation if processing resources have not been sufficient to deactivate the remaining word candidates. A second question is whether the size of the facilitatory item repetition effect is affected by time compression. Given that repetition effects are normally maximal in size at short lags (cf., e.g., Blumstein et al., 2000), they are expected to be fast and thus to be relatively unaffected by time compression.

By investigating whether and how time compression interferes with priming effects of overlapping or same items, we can study the time courses of the opposite effects of item inhibition and item facilitation.

\section{Method Part I}

\subsection{Materials}

The same Dutch language materials were used as in Janse (2006). There were 30 prime-target pairs. The targets were polysyllabic because it is easier to obtain significant inhibition effects with greater amounts of initial overlap. The magnitude of the inhibitory priming effect is determined by the size of the competitor set: the longer a competitor competes with the target word, the fiercer the competition (Dufour \& Peereman, 2003).

For each target, there were three types of primes. The first prime condition was an unrelated baseline condition: prime and target did not share phonemes and were not semantically related (e.g., routine - pyjama 'routine-pyjamas'). This unrelated baseline was chosen rather than an 'empty' or no prime baseline. If all lexical entries of the mental lexicon are involved or co-activated in the competition process, then recognition of any prime will produce some lateral inhibition of targets. In the present study, in both the normal-rate and time-compressed conditions, inhibition due to initial overlap or facilitation due to repetition was estimated, relative to broad inhibition due to recognition of any item (see for a similar choice, Kouider \& Dupoux, 2005).

The second prime condition was the initial-overlap condition in which primes and targets shared a number of initial phonemes (e.g., piano-pyjama 'piano-pyjamas'). Mean number of overlapping initial phonemes in the overlap condition was 3.5 (mean number of phonemes in targets 5.7). The mean size of the cohort, evaluated before

\footnotetext{
${ }^{1}$ A first short version of this study was presented at the 9th European Conference on Speech Communication and Technology Interspeech, Lisbon (Portugal), September 2005.
} 
the isolation point, was 2.3. The third prime condition was the identity condition in which prime and target were the same word (e.g., pyjama-pyjama). Prime Type thus formed one factor in the experimental design. The second factor in the design was rate of presentation of the prime. Primes were presented either at normal-rate or at a faster rate due to time compression (but note that targets were always presented at normal-rate). The same amount of time compression was chosen as in Aydelott and Bates (2004): prime words were compressed to $50 \%$ of their original duration.

Apart from these 30 prime-target test pairs, there were 102 filler pairs. Filler pairs consisted of 30 polysyllabic word-nonword pairs, 36 monosyllabic word-word pairs, and 36 monosyllabic word-nonword pairs, so that the subjects would have to give a NO response equally often as a YES response during the lexical decision experiment. Furthermore, the relatively high number of fillers was mixed with the test material to lower the relatedness proportion (relatedness meaning phoneme overlap between prime and target). Half of the primes (of test and filler materials) were presented in the time-compressed condition, and half were presented at normal-rate. Additionally, six practice item pairs were recorded to familiarize the subjects with the task of lexical decision on the second member of a word pair.

The materials were recorded by a male native speaker of standard Dutch with a clear speaking style. He read the stimulus words in isolation and at a normal-speaking rate. The materials were recorded on digital audiotape with a Sennheiser microphone. They were fed as digital input into the computer and downsampled to $32 \mathrm{kHz}$. Time-scale modification of the primes was applied with the PSOLA technique, as implemented in the speech-editing program PRAAT (www.praat.org). All words and nonwords were stored as separate sound files.

\subsection{Procedure}

Auditory presentation of primes and targets was pairwise, instead of the listwise presentation in Janse (2006). If time compression interferes with processing of the prime, this effect may be short-lived, which is why the intervening prime-target interval needed to be short $(50 \mathrm{~ms})$. Furthermore, the use of short intervening interstimulus interval $(50 \mathrm{~ms})$ minimises the possibility of strategic expectancybased processing. Because each target word was presented in six conditions ( 3 Prime Types $\times 2$ Prime Presentation Rates), and to avoid multiple presentations of a target to the same subject, the 30 targets were distributed over six lists according to a Latin-square design. These six lists were presented to six different subject groups.

Subjects were seated in a sound-insulated booth, wearing closed earphones. An experimental software program was used to present the subjects with the materials. This program randomised the order of the item pairs and kept track of the subject's lexical decision and response time.
Subjects were asked to give a lexical decision response to the second member of the pair by pressing either of two buttons on a response box. Subjects were instructed to respond with their dominant hand for a YES response, and with their non-preferred hand for a NO response. The experiment lasted about $11 \mathrm{~min}$.

\subsection{Subjects}

Sixty young, non-brain-damaged subjects participated in the experiment: 10 listeners were assigned to each of 6 experimental lists. They were between 18 and 30 years of age and received $€ 5$ for their participation. They were all native speakers of Dutch, and they reported no hearing problems.

\section{Results Part I}

Lexical decision times were measured from target onset. Only correct YES responses to the targets were analysed. Table 1 shows the mean RTs in the three prime conditions, broken down by Prime presentation rate. Additionally, accuracy rates are given (in parentheses).

Fig. 1 displays the size of the priming effects (relative to the unrelated baseline condition) for the two prime presentation rates.

Response times were logtransformed $(\log \mathrm{RT})$ to normalise the data distribution. The transformed data were analysed in Repeated Measures ANOVAs with either subjects or items as repeated measures to test the effects of Presentation Rate and Prime Type. In the subject analysis, subjects were nested under Experimental List. Since Repeated Measures ANOVAs require an equal number of observations per participant or per item (so e.g., 30 observations for each participant, i.e., 5 observations in each of the 6 conditions per participant). If one or more observations are missing (due to a participant's incidental incorrect decisions), the analysis should either be run on each participant's mean in that condition, or the missing observations need to be imputed, which is what was done here. Missing observations due to incorrect decisions were imputed by each subject's mean in that condition in the subject analysis, and by each item's mean in that condition in the item analysis (cf. Table 1 for the lexical decision accuracy rates in each cell). ${ }^{2}$ The analyses showed that there was no overall main effect of Presentation Rate $\left(F_{1}(1,54)<1\right.$, n.s.; $F_{2}(1,29)<1$, n.s. $)$ : responses to targets were not affected by the presentation rate of the preceding prime. The effect of Prime Type was highly significant $\left(F_{1}(2,108)=85.5, p<.001 ; F_{2}(2,58)=73.0, p<.001\right)$. A post hoc analysis (with Bonferroni adjustment for multiple

\footnotetext{
${ }^{2}$ The results were highly similar in Univariate ANOVAs which can deal with missing values (a significant Prime Type effect $\left(F_{1}(2,108)=84.6\right.$, $\left.p<.001 ; F_{2}(2,58)=69.9, p<.001\right)$ and an interaction between Prime Type and Rate $\left(F_{1}(2,108)=3.04, p=.048 ; F_{2}(2,58)=3.15, p=.050\right)$; and no main effect of Rate).
} 
Table 1

Lexical decision performance in different prime conditions: mean response times (in ms; and standard errors between brackets) and accuracy rates (in $\%)$

\begin{tabular}{llllll}
\hline & \multicolumn{2}{l}{$\begin{array}{l}\text { Target following } \\
\text { normal-rate prime }\end{array}$} & & \multicolumn{2}{l}{$\begin{array}{l}\text { Target following } \\
\text { compressed prime }\end{array}$} \\
\cline { 2 - 3 } \cline { 5 - 6 } & Mean RT & Accuracy & & Mean RT & Accuracy \\
\hline Unrelated & $904(11)$ & 98 & & $888(10)$ & 97 \\
Overlap & $939(9)$ & 99 & & $939(10)$ & 97 \\
Identical & $821(11)$ & 98 & & $846(12)$ & 98 \\
\hline
\end{tabular}

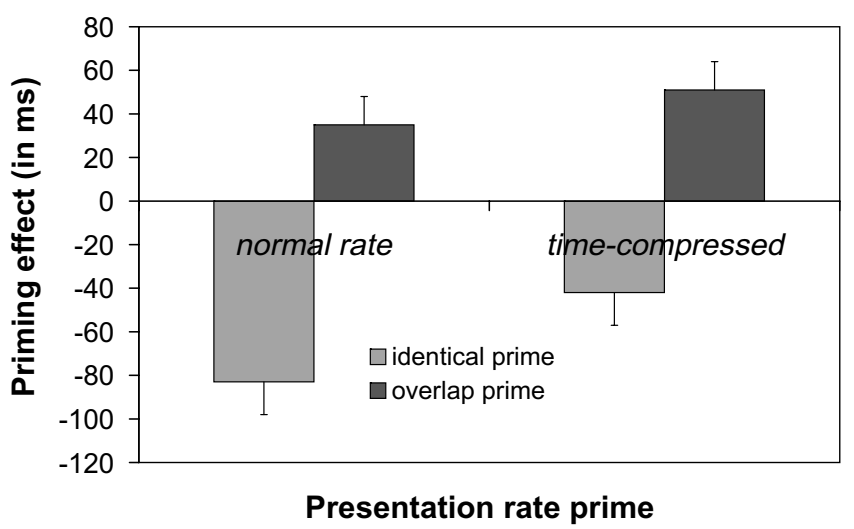

Fig. 1. Priming effects in the identity condition (RT identical conditionRT unrelated condition) and overlap condition (RT overlap condition$\mathrm{RT}$ unrelated condition), at two prime presentation rates.

comparisons) showed that all three prime conditions differed significantly from each other (collapsed over the two rates, and at each rate separately: all $p$-values $<.005$ ). The Rate by Prime Type interaction was significant as well, albeit marginally by items $\left(F_{1}(2,108)=3.25, p=.043\right.$; $\left.F_{2}(2,58)=3.04, p=.057\right)$. There was no main effect of Experimental List $\left(F_{1}(5,54)<1\right.$, n.s. $)$.

To investigate the interaction of Rate by Prime Type further, two subset analyses were run, each time leaving out one Prime Type condition (but note the increased risk of a Type I error in such subset analyses). Fig. 1 suggests that the size of the inhibition effect is relatively unaffected by presentation rate: the subset analysis with identical prime condition excluded showed no interaction between Rate and Prime Type $\left(F_{1}(1,54)=1.12\right.$, n.s.; $F_{2}(1,29)<1$, n.s.). The identity priming effect is somewhat smaller in the time-compressed condition $(42 \mathrm{~ms})$ than in the normal-rate condition $(83 \mathrm{~ms})$ : subset analysis with overlap condition excluded showed a significant interaction between Rate and Prime Type $\left(F_{1}(1,54)=6.96, p=.011\right.$; $\left.F_{2}(1,29)=4.54, p=.042\right)$.

Thus, unlike the results of Aydelott and Bates (2004), the inhibitory effect was not reduced in the time-compressed condition. Inasfar as there was an interaction between effects and rate, it was due to a decreased identity priming effect in the time-compressed condition. This same effect was seen in the masked priming study of Kouider and Dupoux (2005): the further the prime was time-compressed, the smaller the identity priming effect on the uncompressed target. This decrease in effect size may be related to a smaller sublexical component: even though the same word is repeated, the acoustic form is different.

\section{Discussion Part I}

The central question in Part I was whether and to what extent time compression interferes with the effects of item overlap and item repetition, such that a non-brain-damaged population could be made to perform aphasic-like if put under time pressure. With respect to the item overlap effect, the present results show that time compression did not modulate lexical-level inhibition. This contrasts with the Aydelott and Bates (2004) results in which increased processing load due to time compression was shown to interfere with sentence-level inhibition.

The crucial point raised in sentence-priming studies such as Moll et al. (2001) and Aydelott and Bates (2004) is that facilitation and inhibition are qualitatively different: the first being a fast and automatic process of spreading of activation, whereas the second seems to be a later and more demanding process. In Janse (2006), in which the same materials were used as in the present study, Wernicke's aphasic patients showed facilitation in the overlap condition. Even after several intervening items, co-activated word candidates showed persisting activation for the Wernicke's aphasic patients, which is in stark contrast with the fast deactivation of co-activated candidates found in the present study with unimpaired listeners. Clearly, time compression did not elicit aphasic behaviour in healthy subjects in the present study. This could be related to either of the following two factors. First, time compression (to $50 \%$ of the original duration) of a sentence may be more demanding than time compression of a single word which was originally produced as a clear isolated utterance. If so, the increase in processing load may not have been comparable to that in the Aydelott and Bates (2004) study. However, further time compression might have interfered with the word's intelligibility. A second explanation, as already noted in the introduction, is that inhibitory sentence priming effects may be slower to build up than lexical-level inhibition effects. It is easier to interfere with relatively slow sentence-level processes than with the fast process of lexical deactivation. Even though the processes of lexical activation and deactivation can be impaired separately and reflect different underlying mechanisms, the present results show that both processes are fast in unimpaired auditory lexical-processing. If anything, time compression yielded a decreased repetition effect, but the size of the inhibitory overlap effect was unaffected.

In Part II, the focus is on spoken-word processing, more specifically, the effects of item overlap and item repetition, in aphasic patients. Lexical activation (e.g., target $=$ camel) was studied following an overlapping item (e.g., prime $=$ camera $)$ and following presentation of the target itself (prime $=$ camel). This was done to evaluate whether and to which degree co-activated competing lexical candi- 
dates remain active even after one candidate has been recognised. Performance of anomic patients was specifically investigated to study whether and how their performance deviates from the control group.

Different results were expected for different aphasia types: given their deactivation deficit, Wernicke's aphasic patients were expected to show the smallest difference between overlap-prime and repetition-prime conditions. The results of the Broca's aphasic patients in Janse (2006) were less clear. They showed a facilitatory effect of item repetition, but a small and insignificant effect of item overlap. Even though nonfluent patients may initially underactivate the lexicon, they were expected to inhibit co-activated lexical items and thus to show a clear difference between overlap and repetition conditions. Given anomic patients' good spoken-language comprehension, their performance was hypothesised to pattern with that of Broca's aphasic patients rather than Wernicke's aphasic patients. In addition to separate data analyses per aphasia syndrome, the results were also analysed in a more continuous way by relating them to different diagnostic measures. The choice to also include anomic patients yields more diverse performance across the hypothesised continuum between normal and aphasic performance. The more continuous analysis of the results allows an investigation whether a common disturbed (activation spreading) process may underlie verbal short-term memory impairments as well as problems in spoken-word-processing.

\section{Method Part II}

In Janse (2006), two or three items intervened between targets and their primes (which were either unrelated or partially overlapped). The repetition effect, however, could only be investigated over many more intervening items, because each target was presented once in each block of items (first in the overlap condition, and then in the second block in the overlap condition, or vice versa). The present study (Part II) was set up such that overlap and repetition effects could be established for equal numbers of intervening items. Furthermore, the number of intervening items was varied: the lag was either short (one item intervened between prime and target), or long (four items intervened). The choice to always have at least one item intervening between prime and target was based on the Janse (2006) results in which persistent competitor activation was seen, given a range of one to five intervening items between prime and target. Furthermore, relations between nearby items might be less obvious to participants if there is always at least one item (rather than none) in between prime and target. The Lag manipulation was introduced to investigate the time course of lexical activation and deactivation.

\subsection{Materials}

An experimental design which allows a comparison between overlap and repetition effects entails that this com- parison should be made across different items. Therefore, the item set used in the previous study (Janse, 2006) and in Part I did not suffice: more items had to be included. Three sets of 24 polysyllabic target items (either 2 or 3 syllables long) were selected, given that there were three prime conditions (unrelated, overlap and identical conditions). The three sets were matched in terms of frequency of occurrence and word length (in terms of number of syllables). The three condition sets did not differ significantly in mean $\log$ frequency of occurrence $(F(2,69)<1$, n.s. $)$ or mean word length in phonemes $(F(2,69)<1$, n.s. $)$. Primes in the overlap condition showed a word-initial phoneme overlap of 2-5 phonemes to the target (mean $=3.5 ; S D=0.7$ ): e.g., prime and target of the pair koffie-koffer 'coffee-suitcase') share three initial phonemes. Targets in the overlap condition had a mean number of phonemes of 5.8 (range $4-7 ; S D=0.9$ ). Primes in the unrelated condition did not show phoneme overlap and were not semantically related to the target (as in the prime-target pair premie-borstel 'premium-brush'). Target duration did not differ either for the three item sets $(F(2,69)=1.02$, n.s. $)$.

Both studies I and II investigated the time course of the effects of lexical activation and deactivation. To investigate whether time compression could temporarily interfere with item inhibition in Part I, presentation of primes and targets was chosen to be pairwise because this way of presentation allows very short intervals between primes and targets (note that lexical activation was also successfully investigated in aphasic patients with paired priming with such short (50 ms) ISIs: cf. Utman et al., 2001; Kittredge, Davis, \& Blumstein, 2006, or with list priming with 0 intervening items, cf. Blumstein et al., 2000). However, the current study was set up to investigate the time course of the priming effects of item overlap and item repetition, and deactivation was expected to be slowed in the aphasic population. Therefore, presentation of primes and targets in Part II was not pairwise because interstimulus intervals that would be sufficiently long for deactivation to show up in aphasic patients might elicit strategic response behaviour in the control group, because of obvious pairing of primes and targets.

Within each condition, half of the targets (12) were presented with one item intervening between prime and target; the other half of the targets were separated from their prime by four items. There were several types of filler items. First of all, the total number of YES and NO responses had to be more or less balanced: all in all, there were 144 real words and 136 nonwords, yielding a total of 280 targets for lexical decision. Items that intervened between the members of one prime-target pair could be nonwords or real words (such as the prime belonging to another prime-target pair). Secondly, the design should also include overlapping and repetition of nonwords because subjects might otherwise know that overlap or identity always meant a YES response. This led to the inclusion of 24 nonwords that followed the 24 targets of the unrelated condition: e.g., the unrelated prime-target pair premie - borstel 
('premium-brush') would be followed by the nonword bormer. Thus, of the 136 nonwords, 24 showed overlap to a real-word item, and 24 formed repetitions of an earlier presented nonword.

Stimuli were recorded onto digital audio tape by a female native speaker of Dutch in a soundproof booth using a Sennheiser microphone. The recorded stimuli were downsampled to $32 \mathrm{kHz}$ and each item was stored as a separate file.

\subsection{Procedure}

Since the target items were different items in the different prime conditions, the experimental design was within-subject. Because of the prime-target relations and the Lag factor, order of presentation could not be randomised for each participant. Two presentation orders were constructed: each participant (from either the control group or the aphasic group) was assigned to either of the two presentation order lists.

Subjects were seated at a table, wearing closed headphones. The experimental software programme TEMPO (Motta, Rizzo, Swinney, \& Piñango, 2000) was used to present the subjects with the auditory materials. Subjects were asked to give a lexical decision response to each auditory item as fast and as accurately as possible by pressing either of two buttons (labelled YES and NO) on a response box. There was a $3 \mathrm{~s}$ window during which the response could be given. After this time window, the experiment proceeded following a $1 \mathrm{~s}$ pause before the next trial. During the practice session, meant to familiarize subjects with the task, each participant's performance was monitored. All subjects (control and aphasic) were instructed to respond with their non-dominant hand for both a YES response and a NO response and to respond as quickly and as accurately as possible. They were informed that they could not correct their response once given. The experiment consisted of two blocks: subjects could pause in between the two blocks if they liked.

\subsection{Subjects}

Twenty-two aphasic patients volunteered to participate in the study. They were recruited via several rehabilitation centres in the Netherlands where they received speech/language therapy. They were all at least 3 months post-onset at the time of testing. Design and procedure of the study were approved by the Medical Ethics committee of the University Medical Centre in Groningen. All patients and control participants gave their informed consent. The aphasic patients had been diagnosed on the basis of the Dutch version of the Aachen Aphasia Test (Graetz, de Bleser, \& Willmes, 1992) as part of their speech and language therapy program. Mean age of the aphasic patients was 53 years old (range $27-70 ; S D=13$ ). Each aphasic participant (excepting one) also performed a nonword discrimination task (PALPA 1, taken from the Dutch version of the
PALPA; Bastiaanse, Bosje, \& Visch-Brink, 1995) as part of the present study.

Additionally, 10 non-brain-damaged control subjects ( 5 men, 5 women) volunteered to participate in the experiment. Their mean age was 54 years (range 37-68; $S D=9.4$ ). All patients and control subjects were native speakers of Dutch with no reported history of hearing difficulties.

Of the 22 aphasic patients, 7 patients were nonfluent (all of them, excepting NF6, had verbal apraxia). Patient NF6 was diagnosed by the AAT as having Wernicke's aphasia, but his spontaneous speech was agrammatic. The majority of the 15 fluent aphasic patients were diagnosed as suffering from anomic aphasia: only 3 had a Wernicke's aphasia diagnosis. Patient information is presented in Table 2 below.

\section{Results Part II}

Lexical decision time was measured from word onset. Extreme outliers (RTs longer than $3 \mathrm{~s}$ ) were excluded (this led to exclusion of 11 out of 1565 valid observations in the aphasic patients' data: 4 in the unrelated condition, 5 in the overlap condition; 2 in the repetition condition). The results for the aphasic patients are first presented without further subclassification in aphasia types. Mean response times (measured in ms from word onset) for correct YES responses to the targets for the control and aphasic subjects are presented in Fig. 2. Accompanying accuracy rates are given in Table 3.

Accuracy rates were first arcsine transformed and then fed into an ANOVA with subjects (nested under Subject Group: aphasics vs. controls) as repeated measures to test the effects of Prime Type, Lag and Subject Group. There were significant main effects of Prime Type $(F(2,60)=$ $3.20, p=.048)$ and of Subject Group $(F(1,30)=8.35$, $p=.007)$. The factor Lag was not significant $(F(1,30)=1.70$, n.s. $)$. The Prime Type by Subject Group interaction was significant $(F(2,60)=3.89, p=.026)$, but the interactions between Lag and Subject Group $(F(1,30)<1, n . s$.$) and that between Prime Type and Lag$ $(F(2,60)=1.13$, n.s. $)$ were not. Multiple pairwise comparisons were made (with Bonferroni adjustment) to test the accuracy rate differences between prime conditions within each subject group. For the control subjects, accuracy rates were similar in all three conditions: none of the pairwise comparisons was significant. For the aphasic subjects, accuracy rate in the overlap condition (cf. Table 3) differed significantly from the unrelated condition $(p<.001)$, and also from the repetition condition $(p=.001)$.

The RT results of Fig. 2 are also presented in Fig. 3, now broken down by the factor Lag (short- vs. long-lag).

RT values were transformed to $\log$ RTs to normalise the data distribution. The transformed RT results were analysed in an ANOVA with subjects (nested under Subject Group) as repeated measures to investigate the effects of Subject Group, Prime Type and Lag. The ANOVA showed 
Table 2

Patient information

\begin{tabular}{|c|c|c|c|c|c|c|c|c|c|}
\hline Patient & $\begin{array}{l}\text { AAT } \\
\text { classification }\end{array}$ & $\begin{array}{l}\text { Age at } \\
\text { testing }\end{array}$ & Sex & Etiology & $\begin{array}{l}\text { Months } \\
\text { post-onset }\end{array}$ & $\begin{array}{l}\text { AAT token } \\
\text { test }(50-0)\end{array}$ & $\begin{array}{l}\text { AAT repetition } \\
\text { performance } \\
(0-150)\end{array}$ & $\begin{array}{l}\text { AAT auditory } \\
\text { word comprehension } \\
(0-30)\end{array}$ & $\begin{array}{l}\text { PALPA nonword } \\
\text { discrimination } \\
\text { score }(0-72)\end{array}$ \\
\hline NF1 & Broca & 54 & M & CVA-L: ACM & 27 & 48 & 61 & 19 & 54 \\
\hline NF2 & Broca & 53 & M & CVA-L & 120 & 37 & 107 & 24 & 61 \\
\hline NF3 & Global & 43 & $\mathrm{~F}$ & CVA-L & 23 & 50 & 71 & 22 & 57 \\
\hline NF4 & Broca & 45 & $\mathrm{~F}$ & CVA-L & 8 & 40 & 110 & NA & 69 \\
\hline NF5 & Non-classifiable & 70 & M & CVA-L & 5 & 27 & NA & NA & 72 \\
\hline NF6 & Mixed/Wernicke & 55 & M & CVA-L: ACM & 15 & 38 & 118 & 26 & 54 \\
\hline NF7 & Global & 35 & M & CVA-L & 3 & 46 & 72 & 24 & 68 \\
\hline $\mathrm{F} 1$ & Non-classifiable & 69 & M & CVA-L: craniofrontal & 3 & 36 & 146 & 22 & 68 \\
\hline $\mathrm{F} 2$ & Amnesic & 29 & M & Trauma-L: ACM & 4 & 21 & 126 & 24 & 67 \\
\hline F3 & Wernicke & 64 & M & CVA-L: parieto-occ. & 6 & 37 & 52 & 22 & 54 \\
\hline F4 & Amnesic & 64 & M & CVA-L & 4 & 26 & 147 & 17 & 64 \\
\hline F5 & Amnesic & 54 & M & CVA-L & 22 & 27 & 129 & 28 & 71 \\
\hline F6 & Amnesic & 67 & M & CVA-L: ACM & 20 & 33 & 129 & 26 & 67 \\
\hline F7 & Wernicke & 33 & M & CVA-L: art.comm. posterior & 50 & 45 & 85 & 16 & 59 \\
\hline F8 & Amnesic & 43 & $\mathrm{~F}$ & CVA-L: ACM & 22 & 24 & 114 & 24 & NA \\
\hline F9 & Amnesic/rest & 60 & M & CVA-L & 7 & 8 & 130 & 30 & 64 \\
\hline F10 & Mixed/amnesic & 67 & $\mathrm{~F}$ & CVA-L: parieto-occ. & 3 & 17 & 125 & 27 & 65 \\
\hline F11 & Wernicke & 48 & $\mathrm{~F}$ & CVA-L: ACM & 5 & 35 & 87 & 16 & 63 \\
\hline F12 & $\mathrm{NA}^{\mathrm{a}}$ & 65 & M & CVA-L & 6 & NA & 89 & 29 & 68 \\
\hline F13 & Broca- $>$ rest $^{b}$ & 59 & M & CVA-L: ACM & 8 & 11 & 150 & 23 & 63 \\
\hline F14 & Amnesic & 27 & M & Trauma: frontoparietal & 18 & 5 & 129 & NA & 67 \\
\hline F16 & Amnesic & 68 & $\mathrm{~F}$ & CVA-L: frontotemporal & 5 & 13 & 150 & 18 & 68 \\
\hline
\end{tabular}

${ }^{a}$ AAT results were missing for one patient (F12): he had been diagnosed as suffering from aphasia in Germany after having had his stroke while on holiday there. These test results were unavailable and the patient did not want to go through the entire AAT procedure again in the Netherlands. Parts of the AAT and additional tests were carried out in the Netherlands, which showed that he was mainly impaired in word finding and repetition (expressive phonology).

${ }^{\mathrm{b}}$ For this patient the initial AAT diagnosis was $100 \%$ aphasic, more particularly Broca's aphasia. The second diagnosis, after he had recovered significantly, was that he was still aphasic for $48 \%$ (this is computed on the basis of the Token Test and Repetition subpart scores). This diagnosis is termed "rest aphasia".

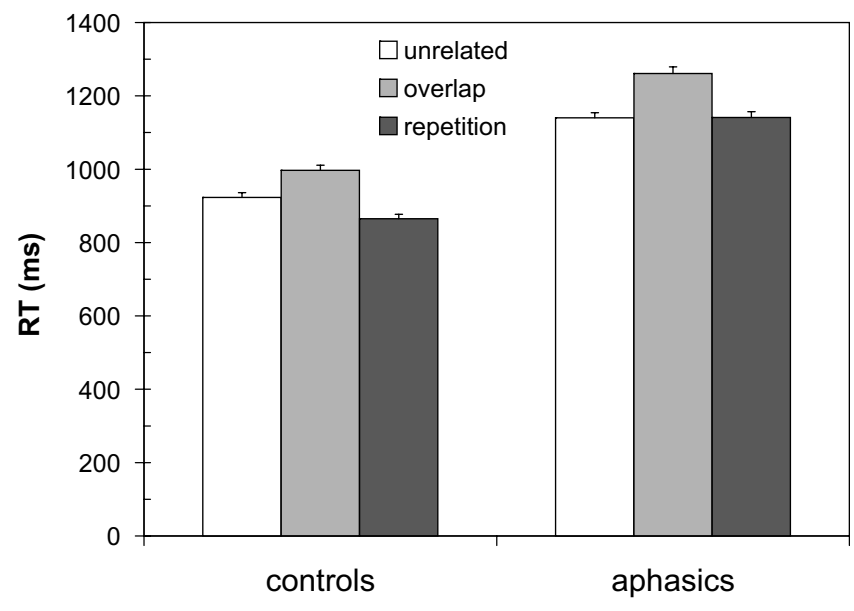

Fig. 2. Mean lexical decision time ( $\mathrm{ms})$ in the different prime conditions for the control and aphasic subjects (bars represent one standard error).

Table 3

Lexical decision accuracy (\%) for both participant groups in the three prime conditions (standard errors in brackets)

\begin{tabular}{llll}
\hline & Unrelated & Overlap & Repetition \\
\hline Controls $(N=10)$ & $99(0.9)$ & $99(0.6)$ & $98(0.7)$ \\
Aphasics $(N=22)$ & $96(0.9)$ & $91(1.7)$ & $95(1.0)$ \\
\hline
\end{tabular}

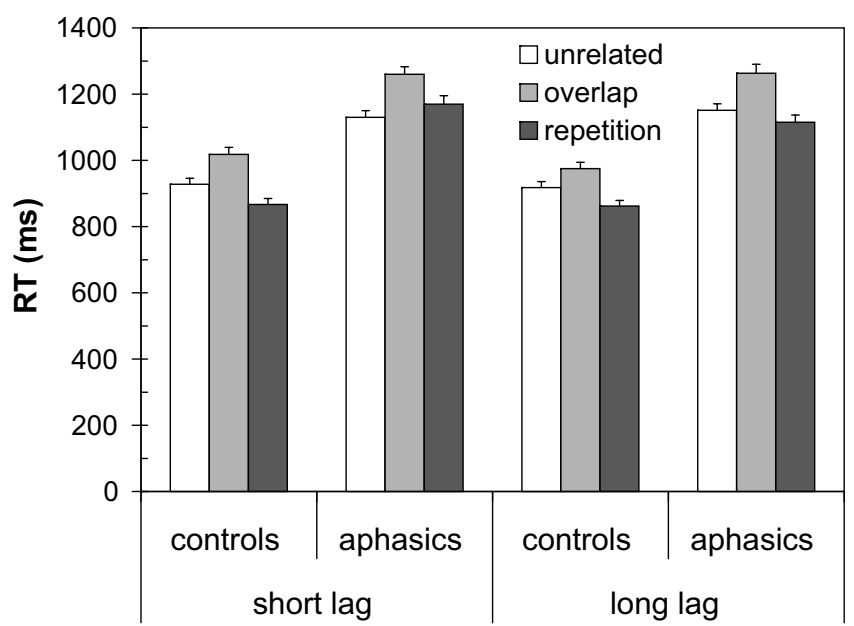

Fig. 3. Mean response time (ms; bars represent one standard error) in the three Prime Type conditions at the two lags.

a significant effect of Prime Type $(F(2,60)=64.7, p<.001)$, and a significant effect of Subject Group (controls vs. aphasics: $F(1,30)=13.0, p=.001)$. The main effect of Lag was not significant $(F(1,30)=3.48, p>.05)$. The interaction between Prime Type and Subject Group was significant 
$(F(2,60)=3.41, p=.033)$. The interaction between Lag and Subject Group was not significant $(F(1,30)<1$, n.s. $)$, nor were the interactions between Prime Type and Lag $(F(2,60)=1.43, \quad n . s$.$) , nor the three-way interaction$ between Prime Type, Lag and Subject Group $(F(2,60)=1.60$, n.s. $)$.

Multiple comparisons were made (with Bonferroni adjustment) to test the differences between the three different prime conditions within each subject group. For the control subjects, responses in the overlap condition were significantly slower than in the unrelated condition $(p<.001)$; and responses in the repetition condition were significantly faster than in the unrelated condition $(p=.021)$. The overlap and repetition condition also differed significantly $(p<.001)$. For the aphasic patients, responses in the overlap condition were significantly slower than in the unrelated condition $(p<.001)$, but responses in the repetition condition were not significantly different from those in the unrelated condition $(p>.5)$. Figs. 2 and 3 above shows that aphasic patients were not consistently fastest in the repetition condition over the two lags. Thus, the Subject Group by Prime Type interaction mainly reflects this lack of a stable facilitatory repetition effect for the aphasic patient group. However, a separate analysis of the aphasic data (by subject) showed a marginally significant interaction between Prime Type and Lag $(F(2,42)=3.22, p=.050)$. Even though multiple comparisons did not show a significant repetition effect at the longlag, relative to the unrelated condition, this interaction suggests that an effect is developing over time.

Table 4

Lexical decision accuracy (\%) of three subgroups of aphasic patients

\begin{tabular}{llll}
\hline & $\begin{array}{l}\text { Unrelated } \\
(\%)\end{array}$ & $\begin{array}{l}\text { Overlap } \\
(\%)\end{array}$ & $\begin{array}{l}\text { Repetition } \\
(\%)\end{array}$ \\
\hline Wernicke's patients $(N=3)$ & 93 & 81 & 93 \\
Nonfluent patients $(N=6)$ & 98 & 94 & 95 \\
Amnesic patients $(N=9)$ & 95 & 94 & 96 \\
\hline
\end{tabular}

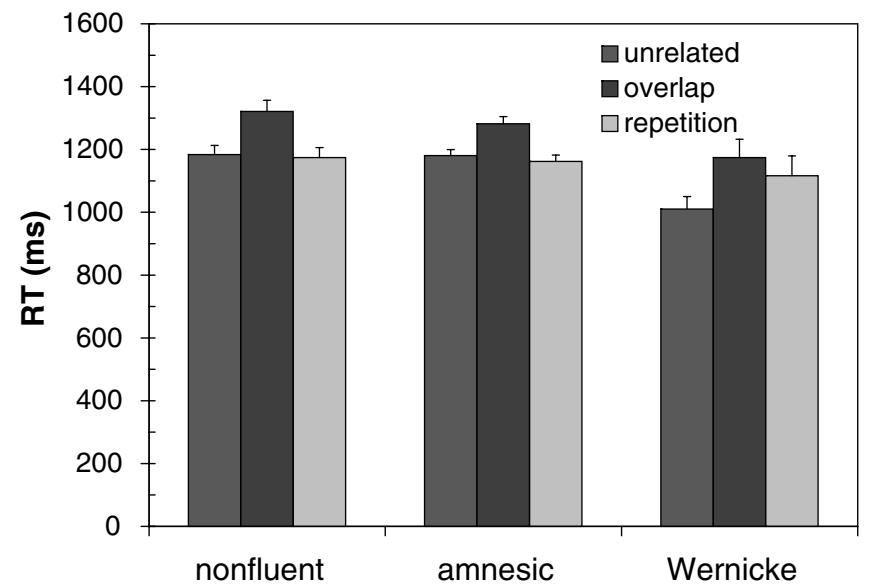

Fig. 4. Mean response times in different prime conditions for three subgroups of aphasic patients (error bars represent one standard error).
Table 2 with patient information shows that the tested aphasic patient group included relatively few patients with a "clear" Wernicke's aphasia (3 patients) or Broca's aphasia. In Table 4 (accuracy) and in Fig. 4 (RT), lexical decision performance of the three subgroups of aphasic patients is shown (Wernicke's patients, nonfluent patients (comprising both Broca's and other nonfluent patients) and anomic patients). Patients with rest aphasia or mixed/unclassifiable types were left out of this graph and table. Results were collapsed over lags.

Table 4 clearly shows that the Wernicke's patients had the lowest accuracy rate, in particular in the overlap condition. The RT results of the Wernicke's patients in Fig. 4 are not similar to those obtained in the previous study: the facilitatory overlap effect found in Janse (2006) was not replicated here for the three Wernicke's patients under study. Secondly, Fig. 4 suggests that there is no difference between the overlap and repetition condition for the Wernicke's patients, whereas these conditions did differ for the other aphasic patients. This pattern was caused by one Wernicke's patient only, however (patient F3). The other two Wernicke's patients both had faster responses in the repetition condition than in the overlap condition. Importantly, Fig. 4 shows that anomic patients, like all other patients, had a significant inhibitory overlap effect, but the repetition effect was not significant for them either. The anomics' performance seems rather similar to that of the nonfluent patients.

Given the heterogeneity of the aphasia syndrome classifications, the aphasic patient results were also analysed in a more continuous way, by relating patients' performance in the present study to their performance in diagnostic background measures, such as parts of the Aachen Aphasia Test (e.g., Token Test performance, Repetition performance, or auditory word comprehension), or to their PALPA nonword discrimination performance, taken as a measure of auditory-verbal short-term memory.

First, relationships between patients' lexical decision accuracy in the present study and their diagnostic performance were assessed. Accuracy was assessed as a difference score in the primed conditions (overlap and repetition conditions), relative to the unrelated condition. For each aphasic patient, accuracy in the item overlap and in the item repetition condition was computed, relative to the unrelated condition. For the overlap effect, accuracy count (number of correct responses out of maximally 24 responses per condition) in the unrelated condition was subtracted from the accuracy count in the overlap condition. This difference score was divided by 24 to make it proportional to the number of observations per condition. For the repetition effect, the same difference score was computed for the repetition condition, relative to the unrelated condition. The sizes of these effects were then related to diagnostic measures. Subjects' performance on the nonword discrimination task (PALPA 1) was the most up-todate background measure because it was administered on the same day as the lexical decision experiment, whereas 
performance on the AAT subparts may have improved since the last AAT was administered. PALPA 1 is a standardised test, which means that performance of an agematched normal control group is also available. Performance is considered to be normal if the score is between 66 and 72 correct out of 72 nonword pairs (11 patients scored below 66; cf. Table 2). For the 22 aphasic patients, accuracy rates in the item overlap condition (relative to the unrelated condition) were significantly correlated with PALPA nonword discrimination accuracy scores (Pearson's $r(22)=.740, p<.001$, two-tailed). Patients' accuracy performance in the repetition condition (relative to the unrelated condition) was also significantly related to PALPA accuracy $(r(22)=.475, p=.025)$ : the better their nonword discrimination performance, the less errors they made in lexical decision.

Patients' scores on the Repetition part of the AAT (subpart of the Aachen Aphasia Test in which patients are asked to repeat sounds and words/phrases of increasing length) were related to accuracy in the overlap condition (relative to unrelated condition accuracy) in the present study: the lower their Repetition performance, the poorer their lexical decision accuracy in the primed condition $(r(21)=.481, p=.027)$. Repetition performance was not related to accuracy performance in the item repetition condition, relative to unrelated condition accuracy $(r(21)=$ .275 , n.s.). Patients' Token Test performance was not significantly related to either accuracy rate difference scores in the item overlap, nor in the item repetition condition $(r(21)$ in both cases $<-.36)$. Patients' performance on the auditory word comprehension subpart of the Aachen Aphasia Test was not significantly related to accuracy difference score in the item overlap condition $(r(19)<.1$, n.s. $)$, nor to that in the item repetition condition $(r(19)=.205$, n.s.).

Secondly, relationships between patients' lexical decision $R T$ effects in the present study and their diagnostic performance were assessed. For each aphasic patient, mean RT effects in the item overlap and in the item repetition condition were computed, relative to the unrelated condition. For the overlap effect, mean RT in the unrelated condition was subtracted from the mean RT in the overlap condition. This RT effect was then divided by the mean RT in the unrelated condition. For the repetition effect, the same difference score was computed for the repetition condition, relative to the unrelated condition. The sizes of these effects were then related to diagnostic measures. PALPA nonword discrimination performance was not significantly related to the size of the overlap effect (Pearson $r(22)=-.159, n . s$.$) ,$ nor to the size of the item repetition effect $(r(22)<-.1$, n.s.). Repetition performance (sounds/words/phrase imitation subpart of AAT) showed a weak relation with the size of the overlap effect $(r(21)=-.430, p=.052)$, but not with the item repetition effect $(r(21)=-.093, n . s$.$) . Token Test$ performance was significantly related to the size of the item overlap effect $(r(21)=.500, p=.021)$, but not to the item repetition effect $(r(21)=-.036, n . s$. $)$. Performance on audi- tory word comprehension (AAT subpart) was not significantly related to either the size of the overlap effect $(r=-.220$, n.s. $)$, or that of the repetition effect ( $r=-.060, n . s$.$) . Summing up the RT effects, only Token$ Test performance and Repetition performance were related to the size of the item overlap effect, but the size of the item repetition effect was not significantly related to any of the diagnostic background measures.

The present correlation data showed significant relations between spoken-word-processing and diagnostic tasks, mainly for lexical decision accuracy differences between the two primed conditions (overlap and repetition) and the unrelated condition. Note also the pattern of the obtained correlations between diagnostic measures and RT effects. The lower the Repetition performance, the larger the overlap effect $(r(21)=-.430, p=.052)$. Similarly, there was a positive correlation between Token Test performance (the higher the score, the worse a patient's performance) and the size of the overlap effect $(r(21)=.500$, $p=.021)$ : the more errors on the Token Test, the larger the overlap effect size. Thus, aphasic patients with poor performance on verbal short-term memory tasks such as PALPA nonword discrimination, Repetition or the Token Test either responded incorrectly in overlap conditions, or took relatively long to respond correctly.

Whereas facilitation of co-activated word candidates was found in Janse (2006), the present results indicate that larger inhibitory RT effects in the overlap condition, rather than smaller or opposite, characterise 'impaired' performance. These different results might be due to two points. First, the impaired deactivation seen in Janse (2006) might be typical for Wernicke's aphasics. Unfortunately, only three Wernicke's aphasic patients were available for testing in the present study. A second explanation cannot be ruled out either. The present and the previous aphasia study differed with respect to the relatedness proportion (meaning the proportion of items showing either partial or full phonemic overlap with neighbouring items). Because primes and targets in the present study could either overlap or be identical with one or four items intervening between them, phonological overlap may have been more salient in the present study than in the previous study (in which items were only repeated over blocks and there were more unrelated fillers). The high relatedness proportion in the present study was also due to the inclusion of identical and overlapping nonwords (cf. Sections 2.1 and 5.1). High relatedness proportions should preferably be avoided given that they may induce strategic effects (cf. Goldinger, Luce, Pisoni, and Marcario (1992) on how high relatedness proportions may yield facilitatory, rather than inhibitory, effects of initial phonological overlap). The higher relatedness proportion in the present item set may have influenced lexical-processing, particularly that of the most 'impaired' patients.

Note, importantly, that these correlations between spoken-word-processing performance and diagnostic measures provide a clearer picture than data analyses per aphasia 
syndrome. Whereas Fig. 4 and the ANOVAs showed no differences between aphasic syndromes, the correlation analyses suggest that similar processes underlie both verbal short-term memory performance and primed lexical decision performance in the present study. This is important with respect to our understanding of the aphasic results. The question whether a reduced-processing-time account might explain the aphasic results will be addressed in Section 7.

\section{General discussion}

Two substudies were carried out to investigate the processes of lexical activation and deactivation as part of spoken-word recognition, both in non-brain-damaged and in aphasic listeners. As mentioned in the introduction, deactivation in the present study could arise either through bottom-up inhibition (deactivation of candidates that no longer fit the acoustic signal) and/or through lateral inhibition among competing candidates. The present choice of materials did not allow a conclusion on which type of inhibition was involved. Either way, the results of studies I and II show converging evidence that inhibition of co-activated candidates was a fast process for all subjects under study. Time compression (Part I) did not interfere with lexical deactivation for the non-brain-damaged subjects. Furthermore, all aphasic patients tested in Part II showed immediate inhibition of co-activated candidates.

Nevertheless, the correlation analyses in Part II pointed out some spoken-word-processing problems in aphasia. Inclusion of anomic patients yielded a better spread of patients across the aphasia severity continuum and relations between diagnostic measures and performance in the present spoken-word-processing study were investigated. Patients with poorer verbal short-term memory skills (as measured in auditory nonword discrimination, repetition of auditorily presented material or in the Token Test) had more difficulty in the item overlap condition, as seen in lower accuracy rates and in larger inhibition effect size. Poor performers on the nonword discrimination task also did more poorly in the item repetition condition (aphasics' accuracy rates were $93 \%$ at the short-lag and $97 \%$ at the long-lag). Furthermore, there was a trend in the aphasics' RT data towards a Lag $\times$ Prime Type interaction (cf. Fig. 3): RTs were somewhat longer in the repetition than in the unrelated condition at the short-lag, but somewhat faster at the long-lag. In other words, item repetition, particularly at the short-lag, also turned out to be a 'difficult' condition for those aphasic patients with the lowest scores on the diagnostic tasks.

What do these combined results mean? The fact that the repetition effect turned out to be slow to accrue, for all aphasics, including anomic patients, fits in with earlier accounts of repetition priming (or the lack thereof). Blumstein et al. (2000) investigated rhyme and repetition priming with Broca's and Wernicke's aphasics and found that the Broca's aphasics, unlike the Wernicke's aphasics and the control subjects, showed no facilitatory repetition effect, if primes and targets were presented as pairs. In Blumstein et al.'s Experiment 2 (2000), in which words were repeated in a listwise presentation with varying numbers of intervening items, a repetition priming effect was found for Broca's and Wernicke's patients, as well as for control adults. Note, however, that the Wernicke's patients showed no priming at the shortest lag (no intervening item), but only at the longer lags $(4,8$ and 12 items intervening).

If representations decay more quickly in short-term memory (particularly in those aphasic patients who performed poorly on the nonword discrimination task), one would expect to find a decreased sensitivity to phonological similarities and differences between prime and target words, which would yield decreased facilitatory and decreased inhibitory effects. ${ }^{3}$ This explanation would account for the absence of a repetition effect (particularly at short lags), but it would not account for those patients' lower accuracy in the overlap and repetition conditions and their increased, rather than decreased, inhibition effect.

The key to explaining the present findings may be in an initial failure to reliably settle on the winning candidate, which involves dealing with co-activated candidates in an appropriate way. Verbal short-term memory skills may be crucial in this stabilisation of the lexical recognition network. Once-activated items should be removed from the candidate pool, either through lateral or bottom-up inhibition. Inhibition of co-activated candidates was a fast process in all patients, but the more impaired patients seemed to show 'disproportionately' large effects (in terms of accuracy and RT effect size). Tentatively, this could be a reaction to the fact that activation of the winner's representation is quickly decaying. This quicker decay in short-term memory then also makes that a new encounter with the same item will be less facilitated, and because the network has not reliably stabilised, may even lead to confusion (particularly in a study with a high relatedness proportion) which shows up in reduced accuracy rates. Furthermore, the quicker decay of the winning representation's activation may also complicate the update of the long-term representation of the recognised word. In Section 1 the two aspects of repetition priming were mentioned: a short-lived repetition effect due to the presence of some 'echo' representation in short-term memory, and the longer-term change in the word's representation responsible for longlag priming effects. It makes sense that if the 'echo' of the recognised word decays more rapidly, this will interfere with the update of the word's representation in long-term memory. As a result, facilitation due to item repetition is a slower process than inhibition of competitors because the update of the word's representation in the mental lexicon is effectuated at a slower rate. The correlation analyses have shown that this is related to the aphasics' problem of

\footnotetext{
${ }^{3}$ This account was brought up by one of the (anonymous) reviewers.
} 
representation or keeping phonological information in store.

Remember that time compression in Part I did not affect the size of the overlap effect, whereas the identity priming effect was smaller in the time-compressed condition (42 $\mathrm{ms})$ than in the normal-rate condition $(83 \mathrm{~ms})$. This was attributed to a smaller sublexical component: whereas prime and target were acoustically identical in the normalrate condition, prime and target differed in duration in the time-compressed condition. Apart from this 'echoic' trace effect, a tentative account of the decreased identity effect in the time-compressed condition is that time compression may have also interfered with the update of the word's long-term representation in the non-brain-damaged subjects: the process may not have been entirely completed yet so as to facilitate the target's recognition fully. This would be in line with an account of aphasia in terms of reduced-processing-time, given that the general picture of the aphasics' results in Part II mainly differed from that of the controls with respect to item repetition. In other words, the attempt to elicit aphasic behaviour in the nonbrain-damaged group in Part I by way of time compression was most successful with respect to the repetition effect. Further research is required to decide whether this 'episodic' account can be held fully responsible or whether this 'slow process' account of repetition priming also contributes to the smaller size of the effect.

Martin and Gupta (2004) and Martin and Saffran (1997) proposed a relationship between severity of lexical-processing impairment and the ability to maintain activation of representations in short-term memory on the basis of a common underlying deficit. Even though their lexical-processing work mainly focusses on naming problems, similar problems in maintaining lexical activation may be found in spoken language-processing, given that there are regions in posterior auditory cortex participating in both speech perception and speech production (Hickok, Buchsbaum, Humphries, \& Muftuler, 2003; Okada \& Hickok, 2006). Martin and Gupta (2004) argued that word learning, immediate serial recall and nonword repetition are related abilities because they draw on the same mechanisms. For nonword repetition, rapid creation of connections is required between an internal phonological representation of the form and a new lexical-level representation that encodes what the sublexical constituents of the word form are and what their serial order is. In order to learn a new word, these connections between lexical and sublexical level must be strong enough to resist decay over time. Furthermore, long-term connection weights between lexical and semantic levels must be created. In language-impaired populations, creation of such connections is impaired. In the Blumstein et al. (2000), aphasic patients, unlike controls, showed no repetition effects for nonwords, not even at the shortest lag. This indicates how rapidly phonological representations decay in aphasic patients. This same rapid decay evidently hampers 'proportionate' deactivation of co-activated lexical items, and the update of the 'winner' representation in long-term memory. The quicker decay of representations slows down this updating process such that facilitatory repetition effects only occur after some time has passed.

More research on language-processing in aphasia is required to gather more evidence on common mechanisms underlying impaired performance in several natural language-processing tasks. Research results and models from auditory word recognition (cf. McNellis \& Blumstein, 2001, and Norris, 1994) should be combined with models based on tasks such as nonword repetition and serial recall (Gathercole \& Baddeley, 1993; Martin \& Ayala, 2004). Both research areas deal with language-impaired populations, the role of verbal short-term memory and spreading of activation within the lexical system. Inclusion of data of anomic patients, and continued attempts to relate psycholinguistic performance to verbal short-term memory measures, will be important for modelling the entire continuum of aphasic speech production and perception. Further insights should also come from a combination of psycholinguistic paradigms and (functional) neuroimaging research, such that maintaining and spreading of activation in the lexicon as fundamental processes underlying speech comprehension and speech production can be understood more fully.

\section{Acknowledgments}

I thank the Dutch rehabilitation centres Heliomare, Sophia Revalidatie, De Hoogstraat, Het Roessingh, Het Rijnlands Revalidatiecentrum, De Vogellanden, De Trappenberg, and Blixembosch, and particularly the speech therapists working there, for their cooperation in this study. Barbara van Olffen (Almere) deserves special thanks for her help in recruiting aphasic patients. I also thank James McQueen (MPI, Nijmegen) for his valuable comments on this study.

\section{References}

Aydelott, J., \& Bates, E. (2004). Effects of acoustic distortion and semantic context on lexical access. Language and Cognitive Processes, 19, 29-56.

Bastiaanse, R., Bosje, M., \& Visch-Brink, E. (1995). PALPA (Dutch edition). Hove: Lawrence Erlbaum Associates.

Baum, S. R. (1997). Phonological, semantic and mediated priming in aphasia. Brain and Language, 60, 347-359.

Blumstein, S. E., Milberg, W., Brown, T., Hutchinson, A., Kurowski, K., \& Burton, M. W. (2000). The mapping from sound structure to the lexicon in aphasia: Evidence from rhyme and repetition priming. Brain and Language, 72, 75-99.

Dell, G. S., Schwartz, M. F., Martin, N., Saffran, E. M., \& Gagnon, D. A. (1997). Lexical access in aphasic and nonaphasic speakers. Psychological Review, 104, 801-838.

Dick, F., Bates, E., Aydelott Utman, J., Wulfeck, B., Dronkers, N., \& Gernsbacher, M. A. (2001). Language deficits, localisation and grammar: Evidence for a distributive model of language breakdown in aphasic patients and neurologically intact individuals. Psychological Review, 108, 759-788.

Dufour, S., \& Peereman, R. (2003). Inhibitory priming effects in auditory word recognition: When the target's competitors conflict with the prime word. Cognition, 88, B33-B44. 
Frauenfelder, U. H., Scholten, M., \& Content, A. (2001). Bottom-up inhibition in lexical selection: Phonological mismatch effects in spoken word recognition. Language and Cognitive Processes, 16, 583-607.

Gathercole, S. E., \& Baddeley, A. D. (1993). Working memory and language. Hove, UK: Lawrence Erlbaum, Associates.

Goldinger, S. D., Luce, P. A., Pisoni, D. B., \& Marcario, J. K. (1992). Form-based priming in spoken word recognition: the roles of competition and bias. Journal of Experimental Psychology: Learning, Memory, and Cognition., 18, 1211-1238.

Gordon, J., \& Baum, S. (1994). Rhyme priming in aphasia: The role of phonology in lexical access. Brain and Language, 47, 661-683.

Graetz, P., de Bleser, R., \& Willmes, K. (1992). Akense Afasietest (AAT). Lisse (The Netherlands): Swets and Zeitlinger.

Heesbeen, I. M. E. (2001). Assessment and recovery of language problems in brain-damaged patients. Unpublished doctoral dissertation. Utrecht University. Veenendaal (The Netherlands): Universal Press.

Hickok, G., Buchsbaum, B., Humphries, C., \& Muftuler, T. (2003). Auditory-motor interaction revealed by fMRI: Speech, music and working memory in area SPT. Journal of Cognitive Neuroscience, 15(5), $673-682$.

Janse, E. (2006). Lexical competition effects in aphasia: Deactivation of lexical candidates in spoken word processing. Brain and Language, 97, $1-11$.

Kittredge, A., Davis, L., \& Blumstein, S. E. (2006). Effects of nonlinguistic auditory variations on lexical processing in Broca's aphasics. Brain and Language, 97, 25-40.

Kouider, S., \& Dupoux, E. (2005). Subliminal speech priming. Psychological Science, 16, 617-625.

Laine, M., Tikkala, A., \& Juhola, M. (1998). Modelling anomia by the discrete two-stage word production architecture. Journal of Neurolinguistics, 11, 275-294.

Marslen-Wilson, W., Moss, H. E., \& van Halen, S. (1996). Perceptual distance and competition in lexical access. Journal of Experimental Psychology: Human Perception and Performance, 22, 1376-1392.

Marslen-Wilson, W., \& Warren, E. (1994). Levels of perceptual representation and process in lexical access: Words, phonemes, and features. Psychological Review, 101, 653-675.

Martin, N. (2000). Word processing and verbal short-term memory: How are they connected and why do we want to know? Brain and Language, $71,149-153$.

Martin, N., \& Ayala, J. (2004). Measurements of auditory-verbal STM span in aphasia: Effects of item, task, and lexical impairment. Brain and Language, 89, 464-483.

Martin, N., \& Gupta, P. (2004). Exploring the relationship between word processing and verbal short-term memory: Evidence from associations and dissociations. Cognitive Neuropsychology, 21, 213-228.

Martin, N., \& Saffran, E. M. (1997). Language and auditory verbal shortterm memory impairments: Evidence for common underlying processes. Cognitive Neuropsychology, 14(5), 641-682.

McClelland, J. L., \& Elman, J. L. (1986). The TRACE model of speech perception. Cognitive Psychology, 18, 1-86.

McNellis, M. G., \& Blumstein, S. E. (2001). Self-organizing dynamics of lexical access in normals and aphasics. Journal of Cognitive Neuroscience, 13, 151-170.
Milberg, W., Blumstein, S. E., \& Dworetzky, B. (1988). Phonological processing and lexical access in aphasia. Brain and Language, 34, 79-293.

Misiurski, C., Blumstein, S. E., Rissman, J., \& Berman, D. (2005). The role of lexical competition and acoustic-phonetic structure in lexical processing: Evidence from normal participants and aphasic patients. Brain and Language, 93, 64-78.

Moll, K., Cardillo, E., \& Aydelott Utman, J. (2001). Effects of competing speech on sentence-word priming: Semantic, perceptual, and attentional factors. Proceedings of the twenty-third annual conference cognitive science society. Mahwah, NJ: Lawrence Erlbaum Associates, pp. 651656.

Monsell, S., \& Hirsh, K. W. (1998). Competitor priming in spoken word recognition. Journal of Experimental Psychology: Learning, Memory, and Cognition, 24, 1495-1520.

Motta, G., Rizzo, F., Swinney, D., \& Piñango, M. M. (2000). Tempo: A software for psycholinguistic and neuroimaging testing. Brandeis University (Dept. of Computer Science), University of California San Diego (Dept. of Psychology) \& Yale University (Dept. of Linguistics).

Norris, D. (1994). Shortlist: A connectionist model of continuous speech recognition. Cognition, 52, 189-234.

Okada, K., \& Hickok, G. (2006). Left posterior auditory-related cortices participate both in speech perception and speech production: Neural overlap revealed by fMRI. Brain and Language, 98, 112-117.

Plaut, D. C., \& Shallice, T. (1993). Perseverative and semantic influences on visual object naming errors in optic aphasia: A connectionist account. Journal of Cognitive Neuroscience, 5, 89-117.

Ratcliff, R., \& McKoon, G. (1996). Bias effects in implicit memory tasks. Journal of Experimental Psychology: General, 125, 403-421.

Ratcliff, R., \& McKoon, G. (1997). A counter model for implicit priming in perceptual word identification. Psychological Review, 104, 319-343.

Slowiaczek, L. M., \& Hamburger, M. (1992). Prelexical facilitation and lexical interference in auditory word recognition. Journal of Experimental Psychology: Learning, Memory and Cognition, 18, 1239-1250.

Thompson-Schill, S. L., Jonides, J., Marshuetz, Cl., Smith, E. E., D'Esposito, M., Kan, I. P., et al. (2002). Effects of frontal lobe damage on interference effects in working memory. Cognitive, Affective, and Behavioral Neuroscience, 2, 109-120.

Thompson-Schill, S. L. (2005). Chapter 11: Dissecting the language organ: a new look at the role of Broca's area in language processing. In A. Cutler (Ed.), Twenty-First Century Psycholinguistics: Four Cornerstones. Mahwah, NJ: Lawrence Erlbaum.

Utman, J. A., Blumstein, S. E., \& Sullivan, K. (2001). Mapping from sound to meaning: Reduced lexical activation in Broca's aphasics. Brain and Language, 79, 444-472.

Wiener, D. A., Connor, L. T., \& Obler, L. K. (2004). Inhibition and auditory comprehension in Wernicke's aphasia. Aphasiology, 18, 599-609.

Yee, E., Blumstein, S. E., \& Sedivy, J. (2004). The time course of lexical activation in Broca's and Wernicke's aphasia: Evidence from eyemovements. Brain and Language, 91, 62-63. 